\title{
Efficacy of Synthetic Pesticides Against Thrips, Thrips tabaci Lindeman (Thysanoptera: Thripidae) on Okra Abelmoschus esculentus (L.) Moench
}

\author{
Hira Mannan ${ }^{1}$, Qurban Ali Nahiyoon ${ }^{2} \& \mathrm{Jilian}_{\mathrm{Li}}{ }^{3}$ \\ ${ }^{1}$ Department of Entomology, Faculty of Crop Protection, Sindh Agriculture University, Tandojam, Sindh, \\ Pakistan \\ ${ }^{2}$ Department of Plant Breeding and Genetics, Faculty of Crop Production, Sindh Agriculture University, \\ Tandojam, Sindh, Pakistan \\ ${ }^{3}$ Key Laboratory of Pollinating Insect Biology of the Ministry of Agriculture, Institute of Apicultural Research, \\ Chinese Academy of Agricultural Science, Beijing, China \\ Correspondence: Jilian Li, Key Laboratory of Pollinating Insect Biology of the Ministry of Agriculture, Institute \\ of Apicultural Research, Chinese Academy of Agricultural Science, Beijing, China. Tel: 86-10-6259-1749. E-mail: \\ bumblebeelj1@hotmail.com
}

Received: January 26, 2021

Accepted: July 2, $2021 \quad$ Online Published: August 15, 2021

doi:10.5539/jas.v13n9p148

URL: https://doi.org/10.5539/jas.v13n9p148

\begin{abstract}
Okra (Abelmoschus esculentus L.) is an essential vegetable crop with good nutritional significance. Insect pests are the major threat for poor production of the okra crop. Thrips of vegetable crops are known to be serious pests on a wide range of fruit, vegetable, flower, and agronomic crops. The present field study was carried out to know the efficacy of different insecticides (acetamiprid 19\% weightable water (ww), lambda $25 \% \mathrm{ww}$, colarphipare $32 \% \mathrm{ww}$, lambda $2.5 \% \mathrm{ww}$ and abamectin $1.3 \% \mathrm{ww}$ ) against Thrips, Thrips tabaci (Lindeman) on okra crop during the year 2019, and observations against T. tabaci (Lindeman) were recorded after $24 \mathrm{hrs}, 48 \mathrm{hrs}, 72 \mathrm{hrs}$ and 07 days of each spray in all the treatments. The pre-treatment count of thrips on okra was non-significant $(P>0.05)$; while the evaluated efficacy of different insecticides against thrips was significant $(\mathrm{P}<0.01)$. It was noted that all the insecticides showed their highest efficacy after 7 days of spray and acetamiprid $19 \%$ weightable water (ww) was more efficient to combat the $T$. tabaci as compared to other pesticides that produced field efficacy of 73.92 and $74.91 \%$ against thrips after 7 days of 1 st and 2nd spray respectively. Abamectin, $1.3 \%$ ww, was reasonably successful, yielding 53.81 and $56.66 \%$ field efficacy against $T$. tabaci (Lindeman) after 7 days of first and second spray. Also, moderately effective was colarphipare $32 \% \mathrm{ww}$, which developed field effectiveness of 56.41 and $61.49 \%$ against $T$. tabaci (Lindeman) after 7 days of first and second spray, respectively.
\end{abstract}

Keywords: efficacy, pesticides, acetamiprid, colarphipare, lambda, abamectin, Thrips, okra

\section{Introduction}

Okra (Abelmoschus esculentus L.) is important vegetable, belonging to the family Malvaceae. It is commonly known as Lady's finger, as well as by several names, including bhindi, okra, okura, lai long ma, gombo, bamia, and quimgombo, in the different geographical regions of its cultivation (Jain et al., 2012). Okra is probably a proficient dietary constituent rather than a staple food crop. Small industries (Surajbala Exports Private Limited, New Delhi, India and Hunan QiyiXinye culture media, Hunan, China) have utilized okra seeds for oil extraction in 2021. The most important facilities for okra are tropics, but subtropical frost sensitive (Oyelade et al., 2003), sensitive to low temperatures (Cheng \& Bradford, 1999), water stress (May et al., 1990; Baloch, 1990; Yadav et al., 2001). Water-sensitive okra is a plant of the richest and lowest for the taste and state of nutritionally rich vegetables (Gopalana et al., 2007).

Thrips, T. tabaci (Lindeman) is a main limiting factor in reducing productivity and has been reported to cause significant economic losses of up to 30-50\% (Nault and Shelton 2012). T. tabaci (Lindeman) is a worldwide pest that has been found on over 300 different host plants, including okra, onion, cabbage, garlic, cereals, and cotton, particularly wheat (Nault \& Hessney, 2010). The damaging stages are nymphs and adults, which feed by rasping 
the leaves and other tissues of plants and sucking the sap, causing silver patches and streaks on the leaves. It can aggravate purple blotch indirectly, in addition to causing direct damage to foliage (Straub \& Emmett, 1992).

Growers are usually exposed to the threat of insecticides, and 145 insect pest species attack the okra plant include mainly bollworms, sucking complexes (thrips, jassid, whitefly, piglets), mites, termites, leaf rollers, and cuts (Dhaka \& Pareek, 2007). An infestation of sucking insect pests is always responsible for considerable economic losses in the production of okra crop in these significant insect pests (Mahal et al., 1994). Many researchers have reported and control of these insect pests through synthetic pesticides (Pawar et al., 1988; Mazumder et al., 2001; Kumar, 2004; Mani et al., 2005; Priya \& Misra, 2007).

Continued use of toxic chemicals as pesticides is still a useful tool to deal with (Wahlla et al., 1998); pesticide resistance in targeted insect pests is also developed (Ahmad et al., 2010). Their efficacy must be assessed time after time to introduce new insecticides to ensure the quality and effectiveness of insect pest control (Singh \& Singh, 1998).

One of the most common and popular controlling method of thrips on okra crop is the use of insecticides. These insecticides must be used with for management or control of any key pest, such as T. tabaci (Lindeman), considering cost economics and environmental damage. In light of this, an experiment was carried out to assess the efficacy of synthetic insecticides against T. tabaci (Lindeman) on okra under field conditions, and compare other insecticides for their effectiveness.

\section{Method}

\subsection{Experiment Site}

This study focused on the efficacy of synthetic pesticides against thrips, T. tabaci (Lindeman) on okra Abelmoschus esculentus (L.) Moench field. This research was performed at the Agriculture Research Institute Tandojam, Sindh, Pakistan, on $15^{\text {th }}$ March 2019. The experiment was laid out in a Randomized Complete Block design (RCBD) with three replicated. Homogenous seeds of the okra variety, such as sabz pari, which is the standard commercial okra variety in Pakistan. This variety was grown on well-prepared ridges. The distance between a height to the ridge was $70 \mathrm{~cm}$. Thinning was performed after a month of sowing, and the plant spacing was maintained by $30 \mathrm{~cm}$. Six plots were designed for six treatments, contained within five synthetic pesticides and one control (untreated). Three times those six plots were replicated to adjust the overall variance.

\subsection{Application of Pesticides}

Pesticides were sprayed on okra crop against T. tabaci (Lindeman), when the apparent population of the T. tabaci (Lindeman) was at an economic threshold level (ETL) 5 to 10 thrips per plant, and the insect population was compared with control (untreated). A spray tank was cleaned carefully to avoid adding mixture before spraying of each insecticide. The knapsack sprayer which was hollow cone nozzles-disc and core type, powered by hand. Usually, in the morning, the spray was conducted.

These synthetic pesticides (acetamiprid 19\% weightable water ww, lambda 25\% ww, colarphipare 32\% ww, lambda $2.5 \% \mathrm{ww}$, and abamectin $1.3 \% \mathrm{ww}$ ) were applied at their recommended dose (Table I). There was a total of six treatments. Five were insecticides, and one was control (untreated).

Table 1. The dose of treatments used against thrips Thrips tabaci (Lindeman)

\begin{tabular}{lll}
\hline Treatments & Active ingredient & Active ingredient Calculated dose Rate $/ 16$ liter water \\
\hline $\mathrm{T} 1$ & Acetamiprid & $19 \% \mathrm{ww}, 25 \mathrm{cc} / 16$ litre water $(500 \mathrm{ml} / \mathrm{acre})$ \\
$\mathrm{T} 2$ & Lambda & $25 \% \mathrm{ww}, 40 \mathrm{~g} / 16$ litre water $(250 \mathrm{~g} / \mathrm{acre})$ \\
$\mathrm{T} 3$ & Colarphipare & $32 \% \mathrm{ww}, 35 \mathrm{cc} / 16$ litre water $(250 \mathrm{ml} / \mathrm{acre})$ \\
$\mathrm{T} 4$ & Lambda & $2.5 \% \mathrm{ww}, 80 \mathrm{cc} / 16$ litre water $(1000 \mathrm{ml} / \mathrm{acre})$ \\
$\mathrm{T} 5$ & Abamectin & $1.3 \% \mathrm{ww}, 30 \mathrm{cc} / 16$ litre water $(500 \mathrm{ml} / \mathrm{acre})$ \\
$\mathrm{T} 6$ & Control (untreated) & (untreated) \\
\hline
\end{tabular}

\subsection{Data Collection}

The thrips pre-treatment observation count was recorded one day before each spray, while thrips post-treatment count was made after 24 hours, 48 days, 72 hours, and one week after each spray of respective insecticides. The population of thrips observed based on three leaves per plant of okra crop (one each from the top, middle, and bottom parts) in its early stage of growth and at the time of harvesting, fruiting bodies were picked out from 
control and treated plots, and compared to observe the efficacy of synthetic pesticides against thrips, $T$. tabaci (Lindeman) on okra and its average was a workout.

\subsection{Statistical Analysis of Data}

Analysis of the difference was carried out on all data collected by the average reduction percentage and preceded by Gomez and Gomez (1984) to determine treatment superiority, Statistical analysis of data with the help of Satistix 8.1 software.

\subsection{Research Design of Experiment}

The experiment was planned as a randomized complete block design (RCBD) for a plant of $3 \times 5$ meters (15 $\mathrm{m}^{2}$ ). Each plot was measuring $1 \mathrm{~m} \times 3 \mathrm{~m}$ had three replications and $1 \mathrm{~m}$ alloys between the plots and blocks. 45 plots with 24 plants stretching $60 \mathrm{~cm} \times 45 \mathrm{~cm}$ per plot were created.

\begin{tabular}{|c|c|c|c|c|}
\hline RI & & RII & & RIII \\
\hline $\mathrm{T} 4$ & \multirow{6}{*}{$\frac{\pi}{2}$} & $\mathrm{~T} 2$ & \multirow{6}{*}{$\underset{⿱ 乛}{2}$} & T5 \\
\hline $\mathrm{T} 2$ & & T6 & & T3 \\
\hline T5 & & $\mathrm{T} 4$ & & T6 \\
\hline $\mathrm{T} 1$ & & T3 & & $\mathrm{T} 2$ \\
\hline $\mathrm{T} 3$ & & $\mathrm{~T} 1$ & & $\mathrm{~T} 4$ \\
\hline $\mathrm{T} 4$ & & T5 & & $\mathrm{T} 1$ \\
\hline
\end{tabular}

\section{Results}

\section{$3.11^{\text {st }}$ Spray}

Different insecticides controlled the insect population to evaluate their efficacy against thrips $T$. tabaci (Lindeman), and the results showed that the differences in thrips population in plots kept for various treatments was non-significant for pre-treatment insect population $(\mathrm{F}=1.11 ; \mathrm{DF}=17 ; \mathrm{P}>0.4355)$; and the thrips population varied significantly when the observation was made after 24 hours of spray $(\mathrm{F}=5.67 ; \mathrm{DF}=17 ; \mathrm{P}=$ $0.0093)$, after 48 hours of spray $(\mathrm{F}=12.32 ; \mathrm{DF}=17 ; \mathrm{P}<0.0000)$, after 72 hours of spray $(\mathrm{F}=37.65 ; \mathrm{DF}=17 ; \mathrm{P}$ $<0.0000)$ and at final observation after seven days of spray $(\mathrm{F}=65.66 ; \mathrm{DF}=17 ; \mathrm{P}<0.0000)$. The $T$. tabaci (Lindeman) mortality recorded at different intervals after treatment due to various synthetic pesticides up to one week after spray is presented in Table-II. The efficacy of insecticides increased with the progression in time after spray. After $24 \mathrm{hrs}, 48 \mathrm{hrs}, 72 \mathrm{hrs}$, and 07 days of the first spray, the efficacy of acetamiprid 19\% ww against thrips was highest $(16.00,29.44,40.73$, and $73.92 \%)$, followed by colarphipare $32 \%$ ww $(17.00,29.98,41.89$ and $56.41 \%$ ), abamectin $13 \% \mathrm{ww}(19.00,27.91,42.26$ and $53.81 \%)$, lambda $2.5 \%$ ww $(20.00,30.40,39.45$ and $48.53 \%)$ and lambda $25 \%$ ww $(5.00,19.25,36.01$ and $46.25 \%)$, respectively. Thrips population was minimized from okra crop in plots where the acetamiprid $19 \% \mathrm{ww}$ was sprayed with $73.92 \%$ insect mortality when recorded after one week of spray. Acetamiprid proved to be maximally effective to combat thrips infestation from okra fields. Among the other evaluated insecticides, colarphipare 32\% ww and abamectin 13\% ww also gave good thrips mortality; but lambda $25 \% \mathrm{ww}$ and lambda $2.5 \% \mathrm{ww}$ remained on the lower side of efficacy against thrips. It was concluded that for achieving effective control of thrips, the pesticide acetamiprid $19 \% \mathrm{WW}$ might be sprayed.

\section{$3.12^{\text {nd }}$ Spray}

The efficacy of synthetic pesticides against thrips $T$. tabaci (Lindeman) population was investigated, and the second spray results revealed that there was a non-significant difference in thrips population between treatments for pre-treatment $(\mathrm{F}=1.12 ; \mathrm{DF}=17 ; \mathrm{P}>0.4071)$; and significant difference in thrips population was recorded when the observation was made after 24 hours of spray $(\mathrm{F}=4.46 ; \mathrm{DF}=17 ; \mathrm{P}=0.0214)$, after 48 hours of spray $(\mathrm{F}=6.67 ; \mathrm{DF}=17 ; \mathrm{P}<0.0056)$, after 72 hours of spray $(\mathrm{F}=11.56 ; \mathrm{DF}=17 ; \mathrm{P}<0.0007)$ and when recorded after seven days of spray $(\mathrm{F}=31.77 ; \mathrm{DF}=17 ; \mathrm{P}<0.0000)$. The second spray efficacy data of certain pesticides against $T$. tabaci (Lindeman) at different intervals after treatment up to one week of spray are shown in Table-III. There was simultaneous improvement in the pesticide efficacy with the advancement of time after spray. After $24 \mathrm{hrs}, 48 \mathrm{hrs}, 72 \mathrm{hrs}$, and 07 days of the second spray, the efficacy of acetamiprid 19\% ww against thrips was $17.99,32.19,42.96$ and $74.91 \%$, followed by colarphipare $32 \%$ ww $(19.94,36.04,51.86$ and 61.49\%), 
abamectin 13\% WW (6.01, 14.36, 44.39 and 56.66\%), lambda 25\% ww (19.06, 33.42, 44.65 and 58.49\%) and lambda $2.5 \%$ ww $(21.03,35.42,43.79$ and $52.28 \%)$, respectively. It is evident from the results that acetamiprid $19 \%$ ww produced a remarkable performance with the highest thrips mortality, and thrips population was diminished to the lowest in plots where acetamiprid was sprayed; while colarphipare $32 \%$ ww and abamectin $13 \%$ ww showed a little recovery, but lambda $25 \% \mathrm{ww}$ and lambda $2.5 \% \mathrm{ww}$ were least effective against the thrips on okra crop. Hence, for dealing with thrips population on okra, the crop may be sprayed with acetamiprid 19\% ww as the mortality of thrips was higher in plots sprayed with acetamiprid compared to the rest of the evaluated pesticides.

Table 2. Effect of synthetic pesticides on the population of thrips, Thrips tabaci (Lindeman) on okra at different intervals after the first spray

\begin{tabular}{|c|c|c|c|c|c|c|c|c|c|}
\hline \multirow{2}{*}{ Treatments } & \multirow{2}{*}{ Pre-treatment } & \multicolumn{2}{|c|}{ 24-hrs } & \multicolumn{2}{|c|}{ 48-hrs } & \multicolumn{2}{|c|}{ 72-hrs } & \multicolumn{2}{|c|}{ 7-days } \\
\hline & & Decrease & Efficacy $\%$ & Decrease & Efficacy $\%$ & Decrease & Efficacy $\%$ & Decrease & Efficacy $\%$ \\
\hline Acetamiprid $19 \% \mathrm{ww}$ & 10.39 & 1.66 & 16.00 & 3.06 & 29.44 & 4.23 & 40.73 & 7.68 & 73.92 \\
\hline Lambda $25 \%$ ww & 11.98 & 0.60 & 5.00 & 2.31 & 19.25 & 4.31 & 36.01 & 5.54 & 46.25 \\
\hline Colarphipare $32 \% \mathrm{ww}$ & 9.61 & 1.63 & 17.00 & 2.88 & 29.98 & 4.03 & 41.89 & 5.42 & 56.41 \\
\hline Lambda $2.5 \%$ ww & 9.83 & 1.97 & 20.00 & 2.99 & 30.40 & 3.88 & 39.45 & 4.77 & 48.53 \\
\hline Abamectin $1.3 \% \mathrm{ww}$ & 10.28 & 1.95 & 19.00 & 2.87 & 27.91 & 4.35 & 42.26 & 5.53 & 53.81 \\
\hline Control & 11.00 & 0.34 & 3.00 & 0.45 & 3.97 & 0.56 & 4.93 & 0.11 & 1.00 \\
\hline S.E. \pm & & & 0.663 & & 0.563 & & 0.446 & & 0.335 \\
\hline LSD 0.05 & & & 1.406 & & 1.265 & & 0.956 & & 0.777 \\
\hline $\mathrm{CV} \%$ & & & 14.43 & & 16.14 & & 15.79 & & 17.44 \\
\hline
\end{tabular}

Table 3. Effect of synthetic pesticides on the population of thrips, Thrips tabaci (Lindeman) on okra at different intervals after the second spray

\begin{tabular}{|c|c|c|c|c|c|c|c|c|c|}
\hline \multirow{2}{*}{ Treatments } & \multirow{2}{*}{ Pre-treatment } & \multicolumn{2}{|c|}{ 24-hrs } & \multicolumn{2}{|c|}{ 48-hrs } & \multicolumn{2}{|c|}{ 72-hrs } & \multicolumn{2}{|c|}{ 7-days } \\
\hline & & Decrease & Efficacy $\%$ & Decrease & Efficacy $\%$ & Decrease & Efficacy $\%$ & Decrease & Efficacy $\%$ \\
\hline Acetamiprid 19\% ww & 8.17 & 1.47 & 17.99 & 2.63 & 32.19 & 3.51 & 42.96 & 6.12 & 74.91 \\
\hline Lambda $25 \%$ ww & 7.66 & 1.46 & 19.06 & 2.56 & 33.42 & 3.42 & 44.65 & 4.48 & 58.49 \\
\hline Colarphipare $32 \%$ ww & 7.27 & 1.45 & 19.94 & 2.62 & 36.04 & 3.77 & 51.86 & 4.47 & 61.49 \\
\hline Lambda $2.5 \%$ ww & 8.13 & 1.71 & 21.03 & 2.88 & 35.42 & 3.56 & 43.79 & 4.25 & 52.28 \\
\hline Abamectin $1.3 \%$ ww & 7.66 & 0.46 & 6.01 & 1.10 & 14.36 & 3.40 & 44.39 & 4.34 & 56.66 \\
\hline Control & 7.62 & 0.23 & 3.02 & 0.30 & 3.94 & 0.27 & 3.54 & 0.01 & 0.13 \\
\hline S.E. \pm & & & 0.402 & & 0.548 & & 0.554 & & 0.492 \\
\hline LSD 0.05 & & & 0.896 & & 1.222 & & 1.234 & & 1.097 \\
\hline $\mathrm{CV} \%$ & & & 7.44 & & 11.71 & & 14.25 & & 15.84 \\
\hline
\end{tabular}

\section{Discussion}

Insecticide resistance has become a significant concern, and new insecticides of the modern formulation are registered to tackle the infestation of insect pests. The goal of this study is to examine the effectiveness of certain synthetic pesticides such as acetamiprid, $19 \% \mathrm{ww}$, lambda, $25 \% \mathrm{ww}$, colarphipare, $32 \% \mathrm{ww}$, lambda, $2.5 \% \mathrm{ww}$, and abamectin, $1.3 \% \mathrm{ww}$ against Thrips, T. tabaci (Lindeman) on okra crop.

The results of this study revealed that all the insecticides tested had the highest effectiveness in combating target insect pests after 7 days of spraying, and acetamiprid's $19 \%$ of ww was more successful than other insect pests achieving field efficacity of 73.92 and $74.91 \%$ against thrips after 7 days of first and second sprays. The effectiveness of abamectin $13 \%$ ww was medium to $53.81 \%$ and $56.66 \%$ against thrips, T. tabaci (Lindeman) after 7 days of first and second sprays also reasonably successful was colarphipare $32 \% \mathrm{WW}$ to achieve field effectiveness of 56.41 and $61.49 \%$ against thrips after 7 days of first and second spray, respectively. acetamiprid, $19 \%$ of ww, reported a higher efficacy against Thrips, T. tabaci (Lindeman), followed by colarphipare $32 \%$ of ww and abamectin $1.3 \%$ of ww, while lambda $25 \%$ of the ww and lambda $2.5 \%$ of the ww have become a less efficient substance in terms of performance. Several previous scholars somewhat supported the above results. Many insecticides are currently present in the local market, but in recent years, the effectiveness of these insecticides was a question mark for farmers Akbar et al. (2012) proposed the maximal 
reduction in the whitefly population (70.54\%) in okra, jassid (73.08\%) and aphid (74.58\%) by novastar, with endosulphan and prophenofos, while Jarwa et al. (2014) demonstrated that Novastar 56 EC (bifenthrien $6 \%$ and abamectin $0.07 \%)$. Novastar also decreased the population with full thrips $(66.48 \%)$. In the sense of pesticide use for okra insect pests, Mahmood et al. (2014) recorded a 92.62\% reduction in the population. Muhammad et al. (2004) tested many synthetic pesticides for their effectiveness with insecticides and found that the management of okra insect pests is effective with all synthetic pesticides. Hassan et al. (2006) analyzed fenoxycarb against sucking the cotton/okra insect pest complex and reported that fenoxycarb application against sucking insect pests was less successful. Dhaka and Pareek (2007) reported that okra is being invaded heavily by the sucking of insect pests. The chemical regulation of sucking insects on okra was found by Bardin et al. (2008) to be more effective than any other control steps. Yadav et al. (2008) observed that endosulfan okra treatment decreased the jassids population to 0.68 per 5 plants at 15 days, while Pareet and Basavanagoud (2008) established that emamectin benzoate and spinosad ( 158.51 and $153.23 \mathrm{q} /$ ha respectively) had the highest marketable fruit yields. Vishwakarma et al. (2009) found that synthetic pesticides were efficient in their efficacy when used alone. Still, the effectiveness in the control of insect pests was significantly improved when synthetic pesticides and plant extracts were mixed. Dimethoate application (234.9 g) and lamb dacyhalothrin (244.9 g) has been successfully controlled for Hasan (2010) with the effectiveness of eight insecticides and with the highest yield. The findings and outcomes of the current research carried out in various parts of the world are similar. Chemicals are recorded in multiple countries and sold with different labels; nevertheless, their effectiveness varied due to genetic resistance in the plant varieties. The factors related to resistance to the suction complex have also been recorded in the studies. Further studies are required as acetamiprid was found to yield desirable results in $19 \% \mathrm{WW}$, particularly because this product gave $100 \%$ effectiveness against thrips, T. tabaci (Lindeman) severely infested okra crop. In contrast, other products were moderate to least effective against thrips, T. tabaci (Lindeman).

\section{Conclusions}

Acetamiprid 19\% ww showed higher efficacy against T. tabaci (Lindeman), followed by colarphipare 32\% ww, abamectin $1.3 \% \mathrm{ww}$, lambda $25 \% \mathrm{ww}$ and lambda $2.5 \% \mathrm{ww}$. All the insecticides showed their highest efficacy after 7 days of spray. Second spray efficacy of synthetic pesticides was relatively higher than their first spray efficacy. Pesticides colarphipare $32 \% \mathrm{ww}$ and abamectin $1.3 \% \mathrm{ww}$ showed some encouraging results regarding their efficacy against the T. tabaci (Lindeman); but lambda $25 \%$ ww or lambda $2.5 \%$ ww did not produce promising results regarding their efficacy against the T. tabaci (Lindeman).

\section{References}

Ahmad, M. S. A., Ashraf, M., \& Ali, Q. (2010). Soil salinity as a selection pressure is a key determinant for the evolution of salt tolerance in blue panic grass (Panicum antidotale Retz.). Flora, 205, 37-45. https://doi.org/ 10.1016/j.flora.2008.12.002

Baloch, A. F. (1994). Vegetable Crops: Horticulture (pp. 529-531). National Book Foundation, Islamabad.

Bardin, M., Fargues, J., \& Nicot, P. C. (2008). Compatibility between biopesticides used to control grey mould, powdery mildew and whitefly on okra and tomato. Biological Control, 46, 476-483. https://doi.org/10.1016/ j.biocontrol.2008.05.012

Dhaka, S. R., \& Pareek, B. L. (2007). Seasonal incidence of natural enemies of key insect pests of cotton and their relationship with weather parameters. Journal of Plant Protection Research, 47(4), 418-419.

Gomez, K. A., \& Gomez, A. A. (1984). Statistical procedures for Agricultural Research (2nd ed., p. 680). John Wiley and Sons, New York.

Gopalan, C., Sastri, S. B. V., \& Balasubramanian, S. (2007). Nutritive value of Indian foods. National Institute of Nutrition (NIN), ICMR, India.

Hasan, W. (2010). Evaluation of Some Insecticides against Spotted Bollworm, Earias vittella (Fab.) on Different okra Cultivars. Trends in Biosciences, 3(1), 210-216.

Hassan, M., Ahmad, F., \& Wakeel, W. (2006). Role of biochemical components in varietal resistance of cotton against sucking insect pests. Pakistan Entomologist, 22(1/2), 69-71.

Henry, E. (2001). Commercial Okra Production (pp. 1-3). University of Arkansas Cooperative Extension Program, University of Arkansas at Pine Bluff, United States Department of Agriculture and County Government Cooperative.

Hunan H. (2021). Qiyi Xinye Culture Media, China. Retrieved January 19, 2021, from https://www. globalsources.com/si/AS/Hunan-Qiyi/6008850060925/Showroom/3000000149681/ALL.htm 
Jain, N., Jain, R., Jain, V., \& Jain, S. (2012). A review on: Abelmoschus esculentus. Pharmacia, 1, 84-89. https://doi.org/10.12966/hc.5.4.2013

Jarwar, A. R., Khuhro, R. D., \& Bhiloo, K. A. (2014). Efficacy of neem oil and neem kernal powder against major sucking pests on brinjal under field conditions. European Academic Journal, 2(6), 7641-7657.

Kumar, A. (2004). Effect of neem-based pesticides on germination of okra, Abelmoschus esculantus Moench Seed. Shashpa, 11(1), 83-85.

Mahal, M. S., Brar, L. S., \& Singh, R. (1994). Effect of variable feeding exposures to jassid, Amrasca biguttula biguttula (Ishida) on seed yield of okra. Journal of Insect Science, 7(2), 125-128.

Mahmood, K., Eijaz, S., Khan, M. A., Alamgir, A., Shaukat, S. S., Mehmood, Z., \& Sajjad, A. (2014). Effects of biopesticides against jassid [Amrasca biguttula (Ishida)] and whitefly [Bemisia tabaci (Genn.)] on okra, International Journal Biological Biotechnology, 11(1), 161-165.

Mani, M., Krishnamoorthy, A., \& Gopalakrishnan, C. (2005). Biological control of lepidopterous pests of Horticultural crops in India. A Review of Agricultural Research, 26(1), 39-49.

Mays, D. A., Buchanan, W., Bradford, B. N., \& Giordano, P. M. (1990). Fuel production potential of several agricultural crops. In J. Janick, \& J. E. Simon (Eds.), Advances in new crops: Proceedings of the First National Symposium NEW CROPS, Research, Development, Economics, Indianapolis, Indiana, October 23-26, 1988 (pp. 260-263). Portland, OR, USA: Timber Press.

Mazumder, N., \& Borthakur, U. (2001). Choudhury, D. Incidence of yellow vein mosaic virus of bhindi Abelmoschus esculentus L., Moench in relation to cultivar and vector population under different sowing dates. Indian Journal of Virology, 12(2), 137-141.

Muhammad, M., Gill, M. A., Aziz, T., Rahmatullah, \& Ahmed, I. (2004). Growth response of cotton cultivars to zinc deficiency stress in chelator-buffered nutrient solution. Pakistan Journal Botany, 36(2), 373-380.

Naeem, M., Iqbal, J., \& Bakhsh, M. A. A. (2006). Comparative study of inorganic fertilizers and organic manures on yield and yield components of mung bean (Vigna radiat L.). Journal Agriculture Social Science, 2, 227-229.

Nault, B. A., \& Shelton, A. M. (2012). Guidelines for managing onion thrips on onion. Veg Edge. Cornell University, Cooperative Extension, Regional Vegetable Programs, 8, 14-17.

Oyelade, O. J., Ade-Omowaye, B. I. O., \& Adeomi, V. F. (2003). Influence of variety on protein, fat contents and some physical characteristics of okra seeds. Journal of Food Engineering, 57(2), 111-114. https://doi.org/ 10.1016/S0260-8774(02)00279-0

Pareet, J. D., \& Basavanagoud, K. (2009). Evaluation of bio-pesticides against brinjal shoot and fruit borer and sucking pests. Annals of Plant Protection Science, 17(2), 459-526.

Priya, B. S., \& Misra, H. P. (2007). Biopesticides for the management of okra fruit borer, Earias vittella (Fabricius). Pest Management in Horticultural Ecosystems, 13(2), 176-179.

S.E.P. Limited. (2021). Retrieved January 18, 2021, from https://www.sbepl.com

Singh, J., \& Singh, K. (1998). Economic threshold for spotted bollworms, Earias spp. in cotton, Gossypium arboreum L. Journal Insect Science, 11(1), 66-68.

Straub, R. W., \& Emmett, B. (1992). Pests of monocotyledon crops. Vegetable Crop Pests (pp. 213-262). Macmillan Press, UK. https://doi.org/10.1007/978-1-349-09924-5_7

Vishwakarma, S., Verma, A., \& Saxena, G. (2009). A Comparative Study on the Toxicity of a Synthetic Pesticide, Dichlorvos and a Neem based Pesticide. Current World Environment, 7(1), 157-161. https://doi.org/ 10.12944/CWE.7.1.24

Wahla, M. A., Tufail, M., Afzal, M., \& Tariq, M. N. (1998). Comparative resistance of some recent releases of cotton cultivars to the insect pests complex, Pakistan Entomologist, 20(1-2), 92-94.

Yadav, J. B., Singh, R. S., \& Tripathi, R. A. (2008). Evaluation of Bio-pesticides against pest complex of okra. Annals of Plant Protection Sciences, 16(1), 492-498.

Yadav, S. K., Dhankhar, B. S., Deswal, D. P., \& Tomer, R. P. S. (2001). Effect of sowing date and plant geometry on seed production and quality of okra, Abelmoschus esculentus L. (Moench) cv. Varsha Uphar, Seed Research, 29(2), 149-152. 


\section{Copyrights}

Copyright for this article is retained by the author(s), with first publication rights granted to the journal.

This is an open-access article distributed under the terms and conditions of the Creative Commons Attribution license (http://creativecommons.org/licenses/by/4.0/). 